\title{
KESESUAIAN LAHAN BUDIDAYA LAUT DI PERAIRAN KABUPATEN BOLAANG MONGONDOW SELATAN, SULAWESI UTARA
}

\section{(Area suitability for mariculture in South Bolaang Mongondow regency, North Sulawesi)}

\author{
Yulianty Adipu ${ }^{1}$, Cyska Lumenta $^{2}$, Erly Kaligis ${ }^{2}$ dan Hengky J. Sinjal ${ }^{2}$ \\ ${ }^{1}$ Program Pascasarjana, Universitas Sam Ratulangi, Manado, Sulawesi Utara. \\ ${ }^{2}$ Fakultas Perikanan dan Ilmu Kelautan Universitas Sam Ratulangi, Manado, Sulawesi Utara.
}

\begin{abstract}
Penelitian dilakukan untuk mengkaji tingkat kesesuaian lahan budidaya laut, khususnya budidaya rumput laut dan budidaya ikan di Kurungan Jaring Apung (KJA) di perairan Kabupaten Bolaang Mongondow Selatan, Provinsi Sulawesi Utara. Penentuan stasiun pengambilan sampel dilakukan berdasarkan identifikasi adanya aktivitas budidaya rumput laut dan budidaya ikan pada KJA di lokasi tersebut Lima stasiun pengamatan yakni lokasi budidaya rumput laut desa Matandoi, dan lokasi budidaya ikan dalam KJ $A$ di desa Deaga, Torosik, Matandoi dan Pinalantungan. Pada tiap stasiun ditentukan satu titik pengambilan sampel air untuk pengukuran parameter kualitas air, serta aspek fisik lain seperti kecepatan arus dan beda pasang-surut air laut. Parameter kualitas air seperti amoniak, $\mathrm{pH}$, suhu, nitrit dan turbiditas diukur menggunakan Water Test Kit AYI-10 in ScienPro, sementara salinitas dan oksigen terlarut (DO) diukur menggunakan Water Tester Horiba. Data yang diperoleh ditabulasi dan ditampilkan dalam histogram. Untuk menentukan tingkat kesesuaian lahan, data dibandingkan dengan baku mutu persyaratan untuk lokasi budidaya rumput laut dan budidaya ikan di KJA. Hasil penelitian menunjukkan bahwa perairan desa Matandoi sesuai untuk lokasi budidaya rumput laut. Perairan desa Pinalantungan, desa Torosik, dan desa Matandoi sesuai untuk lokasi budidaya ikan di KJA, sedangkan perairan desa Dedaga kurang sesuai untuk lokasi budidaya KJA.
\end{abstract}

Kata kunci: kesesuaian lahan, budidaya, rumput laut, K9A Belaang Mongondow Selatan.

This study was aimed to study the suitability level of waters in South Bolaang Mongondow Regency, North Sulawesi Province, for seaweed culture and fisheulture in floating net cage (KJA). The stations for water sampling were appointed based on the occurrence of the seaweed culture and finfish culture in KJA in the area. Five stations were appointed, where one station representing seaweed culture area (Matandoi village waters), while four stations representing the floating net cage culture areas (Deaga, Torosik, Matandoi and Pinalantungan village waters). At each station, one point was appointed for sampling of waters for the measurement of water quality parameters and for assessment of other physical features of waters body such as, current velocity, wave height and tide level. The other water quality parameters such as, ammonia, $\mathrm{pH}$, temperature, nitrite, and turbidity were-measured using Water Test Kit AYI-10 in ScienPro, whereas dissolve oxygen (DO) and salinity were measured using Horiba Water Tester. The collected data were then tabulated and presented in histogram. To analyze the level of the suitability of the area for seaweed culture and floating net cage culture, the obtained data were compared to the standard water quality for the location of seaweed culture and floating net cage culture. The results show that, the territorial waters of Matandoi village is suitable for seaweed culturearea. The territorial waters of Pinalantungan village, Torosik village and Matandoi village are suitable for floating net cage culture area, while territorial waters of Deaga village is less-suitable for floating net eage culture area.

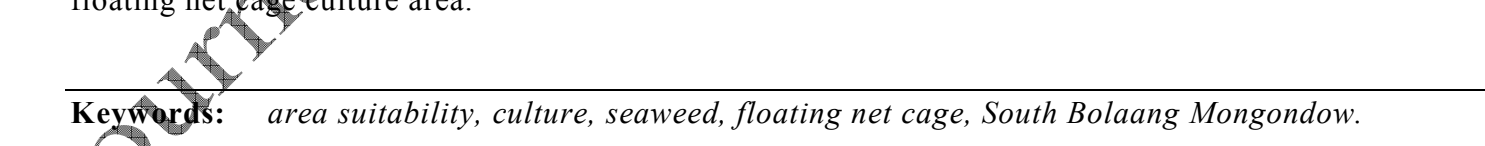

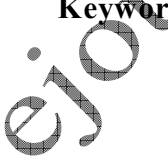

PENDAHULUAN

Indonesia dewasa ini melalui Kementerian Kelautan dan Perikanan (KKP) menargetkan peningkatan produksi perikanan budidaya dari berbagai komoditi untuk memenuhi kebutuhan dalam negeri maupun kebutuhan pasar internasional. Sutisna (2011) menyatakan bahwa, konsumsi ikan dalam negeri pada 2014 sebesar 9,31 juta ton, sementara proyeksi produksi perikanan Indonesia
2014 adalah sebesar 22,39 juta ton yang terbagi atas perikanan tangkap 5,5 juta ton dan akuakultur 16,89 juta ton. Data tersebut mengindikasikan proyeksi produksi akuakultur yang menjadi andalan untuk tahun-tahun ke depan.

Menurut Sugama (2011), diantara negaranegara produsen produk akuakultur, Indonesia berada pada peringkat ke-4 negara produsen terbesar di dunia di bawah China, India dan Vietnam, dengan total produksi 1,733 juta ton per tahun 
dengan nilai US\$ 3,2 juta. Sementara, target produksi kultur rumput laut Indonesia pada 2014 sebesar 10 juta ton; target produksi ikan laut (kakap dan kerapu) akuakultur Indonesia pada 2014 sebesar 22,5 juta ton. Sugama (2011) selanjutnya menyatakan bahwa, salah satu dari 3 komoditas utama program KKP adalah rumput laut (Eucheuma sp.), sedangkan kerapu merupakan salah satu dari 8 komoditas unggulan KKP. Sehingga budidaya dari ke dua komoditas tersebut harus digalakkan di semua perairan laut Indonesia. Rumput laut ditetapkan sebagai komoditas utama, karena budidaya rumput laut di Indonesia dan di negara-negara berkembang di Asia Tenggara telah terbukti membuka lapangan kerja baru serta menjadi pendapatan alternatif bagi masyarakat pesisir, dan secara signifikan meningkatkan taraf ekonomi mereka (Nang and Isao, 2006; Salindeho, 2006). Selanjutnya Ramelan (1998) menyatakan bahwa, potensi pengembangan budidaya laut dengan menggunakan jaring apung di Indonesia adalah seluas $375,000 \mathrm{Ha}$, dimana $1 \%$ dari luasan tersebut, yakni $3750 \mathrm{Ha}$ adalah luasan total jaring. Sehingga, budidaya ikan kerapu di KJA merupakan komoditas unggulan untuk KKP.

Berdasarkan informasi di atas, semua daerah Indonesia yang memiliki potensi pengembangan budidaya laut, khususnya budidaya rumput laut dan budidaya ikan di KJA, seharusnya menanggapi tantangan tersebut. Salah satu daerah yang memiliki potensi perikanan dan kelautan yang melimpah dan juga dikenal sebagai pintu gerbang Teluk Tomini adalah Kabupaten Bolaang Mongondow Selatan. Kabupaten ini merupakankabupaten hasil pemekaran dari Kabupaten Bolaang Mongondow Provinsi Sulawesi Utara. Luas w Ilayah kabupaten ini adalah $3.497,46 \mathrm{~km}^{2}$ yaitu wilayah daratan $1.615,86 \mathrm{~km} 2$ dan laut $1.881,60 \mathrm{~km} 2$, dengan panjang garis pantai 294km (Anonimous, 2011).

Potensi pertkanan dan kelautan yang melimpah pada kabupaten Bolaang Mongondow Selatan tersebar pada semua kecamatan yang ada. Kecamatan Pinglosian Timur terdapat 9 desa dimana sebagian besar memiliki wilayah pesisir dan potensi budidaya laut sebesar $1.700 \mathrm{Ha}$. Kecamatan Pinolosian Tengah terdapat 5 desa dan hampir semua desa tersebut memiliki wilayah pesisir dengan potensi budidaya laut $1.700 \mathrm{Ha}$. Kecamatan Pinolosian terdapat 8 desa dan kesemuanya memiliki wilayah pesisir dengan potensi budidaya laut 198 Ha. Kecamatan Bolaang Uki terdapat 18 desa yang kesemuanya memiliki wilayah pesisir dengan potensi budidaya laut $1.800 \mathrm{Ha}$. Kecamatan Posigadan terdapat 14 desa dan potensi budidaya laut
$1.500 \mathrm{Ha}$ (Anonimous, 2011). Keppel dan Salindeho (2004) menyatakan bahwa lokasi dan luas areal potensial untuk budidaya rumput laut di Kabupaten Bolaang Mongondow, khususnya perairan desa Pinolosian dan Pinolosian Timur adalah seluas $675 \mathrm{Ha}$; Desa Molibagu Kecamatan Bolaang Uki dan Posigadan, luas potensial $350 \mathrm{Ha}$.

Usaha pengembangan budidaya perikanan di Bolaang Mongondow Selatan sudah mulai dilakukan dalam beberapa tahun terakhir, namun pengelolaannya belum mempertimbangkan pemanfaatan potensi sumberdaya yang ada secara optimaldan berkelanjutan dengan produksi maksinna. Oléh karena itu perlu dilakukan suatu kajan identifikasi lahan perairan yang potensial untuk dikembangkan usaha marikultur, dengan mengetabui luasan total perairan yang sesuai, komoditas apa yang dapat dikembangkan serta total produksi masing-masing komoditas setiap tahynnya. Departemen Kelautan dan Perikanan (2002) merilis pedoman atau kriteria umum perencanaar kawasan budidaya dimana faktor-faktor yang harus dipertimbangkan dalam perencanaan kawasan budidaya laut adalah: kegiatan di daratan terutama DAS yang dapat mempengaruhi kawasan budidaya laut, seperti pabrik, industri pertanian, pertambangan dan pemukiman; bersinergi dengan semua pemangku-kepentingan dengan tidak memberikan dampak negatif; faktor-faktor hidro-oseanografi; faktor geomorfologi dan faktor sosial kemasyarakatan.

Di beberapa lokasi perairan Bolaang Mongondow Selatan sudah dirintis usaha budidaya rumput laut dan budidaya ikan pada KJA. Berdasarkan informasi dari masyarakat pembudidaya dan pemerintah setempat, pemanfaatan areal budidaya laut yang dilakukan selama ini umumnya tanpa diawali dengan analisa kesesuaian lahan dan kondisi daya dukung lahan serta status lokasi. Dengan demikian para pembudidaya dihadapkan pada berbagai kondisi yang tidak diprediksikan sebelumnya yang dapat mempengaruhi keberhasilan dan keberlanjutan usaha budidaya yang dilakukan. Departemen Kelautan dan Perikanan (2002) menginformasikan bahwa untuk penilaian kesesuaian zonasi kawasan budidaya kakap dan kerapu dengan KJA, parameter yang di nilai adalah: faktor keterlindungan, arus, pasang-surut dan arus pantai, Salinitas, temperatur, DO, kandungan logam berat, arah dan kecepatan angin, topografi pantai (batimetri), substrat, kecerahan, transportasi dan pasar. Sementara untuk penilaian kesesuaian zonasi kawasan budidaya rumput laut, selain faktor-faktor tersebut di atas, juga harus ditambahkan kajian 
menyangkut nutrien yang terkandung serta kesuburan perairan (Landau, 1995).

Untuk menjamin adanya suatu usaha pemanfaatan potensi sumberdaya perairan secara optimal dan berkelanjutan dengan produksi maksimal dari sektor budidaya laut, maka perlu dilakukan suatu kajian ilmiah untuk mengidentifikasi lahan perairan laut yang potensial untuk dikembangkan usaha marikultur. Dengan mengetahui luasan total perairan yang sesuai serta komoditas apa yang dapat dikembangkan, maka perencanaan pengembangan marikultur dapat ditetapkan pemerintah setempat, sehingga target produksi setiap komoditas setiap siklus pemeliharaan dicanangkan.

\section{METODE PENELITIAN}

Penelitian dilakukan di perairan laut Kabupaten Bolaang Mongondow Selatan, mulai FebruariMei 2013. Pengujian sample air dilakukan di Lab. Teknologi Akuakultur, Universitas Sam Ratulangi.

Penelitian ini merupakan penelitian eksploratif dengan mengaplikasikan metode survey dalam rancangannya (Nasution, 2009). Pengumpulan data dilakukan dengan mengkombinasikan teknik penyebaran kuesioner, wawancara langsung dengan narasumber dan observasi lapangan. Prose- dur observasi lapangan dilakukan untuk pengukuran parameter kualitas air pada beberapa stasiun pengamatan, serta observasi untuk menilai tata letak, kondisi lingkungan sekitar serta penentuan keterlindungan lokasi perairan. Penentuan stasiun pengambilan sampel dilakukan berdasarkan identifikasi adanya aktivitas budidaya rumput laut dan budidaya ikan pada kurungan jaring apung di lokasi tersebut, sehingga ditetapkan lima stasiun pengamatan yakni perairan pantai desa Matandoi, Deaga, Torosik, dan Pinalantungan. Pada tiap stasiun ditentukan satu titik pengambilan sámpel đuntuk pengukuran parameter kualitas air. Pyotokol pengambilan sampel air dan penarnganan sampel dalam transportasi dan penyimpanan mengikuti petunjuk dari Effendi (2000). Pengambilan sampel air dilakukan pada titik yang dapat menggambarkan karakteristik keseluruhan badan air. Sampel air disimpan dalam botol plastik baru yang tidak dapat berinteraksi dengan air sampel. Air sampel didinginkan pada suh $^{\circ} 4^{\circ} \mathrm{C}$ selama transportasi dan penyimpanan dearena pada level ini tidak ada aktivitas bakteri. Setiap botol dibungkus dengan plastik hitam, kemudian disimpan dalam cool-box untak thenjaga suhu air tetap pada level $4^{\circ} \mathrm{C}$.

Tabel 1. Matrik kesesuaian lahan perairan untuk budidaya rumput laut Eucheuma spp. Table 1. Suitability matrix for Eucheuma spp. seaweed culture.

\begin{tabular}{|c|c|c|c|}
\hline \multirow{2}{*}{ Parameter } & \multicolumn{3}{|c|}{ Kriteria kesesuaian } \\
\hline & sangat sesuai (S1) & cukup sesuai (S2) & tidak sesuai (N) \\
\hline Keterlindungan & terlindung (teluk, selatk & $\begin{array}{c}\text { cukup terlindung (perairan dangkal } \\
\text { dengan karang penghalang) }\end{array}$ & terbuka (perairan terbuka) \\
\hline Tinggi gelombang $(\mathrm{m})$ & $0,20-0,30$ & $0,10-<0,20:>0,30-\leq 0,40$ & $<0,10:>0,40$ \\
\hline Kecepatan arus $(\mathrm{m} / \mathrm{s})$ & $0,20-0,30$ & $0,10-<0,20:>0,3-\leq 0,40$ & $<0,10:>0,40$ \\
\hline Kecerahan (\%) & $80-100$ & $60-<80$ & $<60$ \\
\hline Kedalaman (m) & & $1-<2:>10-\leq 30$ & $<1:>30$ \\
\hline Substrat dasar & ahan karang, lamun, & pasir sedikit berlumpur & lumpur \\
\hline Nitrat (mg/l) & $0,9-3,0$ & $0,1-<0,9: 3,0-3,5$ & $<0,1:>3,5$ \\
\hline Fosfat (mg/l) & $0,02-1,00$ & $0,01-<0,02:>1,00-2,00$ & $<0,01:>2,00$ \\
\hline Kekeruhan (NTU) & $\leq 10,0$ & $>10,0-\leq 40,0$ & $>40,0$ \\
\hline Oksigen terlarut $(\mathrm{m}$ & $\geq 4,0$ & $2,0-<4,0$ & $<2,0$ \\
\hline Suhu $\left({ }^{0} \mathrm{C}\right)$ & $28-30$ & $25-<28:>30-\leq 33$ & $<25:>33$ \\
\hline Salinitas (ppt) & $28-34$ & $25-<28:>34-\leq 35$ & $<25:>33$ \\
\hline $\mathrm{pH}$ & $7,0-8,5$ & $6,5-<7,0$ & $<6,5:>8,5$ \\
\hline
\end{tabular}

\begin{tabular}{|c|c|c|c|}
\hline \multirow[t]{2}{*}{ Parameter } & \multicolumn{3}{|c|}{ Kriteria kesesuaian } \\
\hline & Sangat sesuai (S1) & Cukup sesuai (S2) & Tidak sesuai (N) \\
\hline Keterlindungan & Terlindung (teluk, selat) & $\begin{array}{l}\text { Cukup terlindung (perairan dangkal } \\
\text { dengan karang penghalang ) }\end{array}$ & Terbuka ( perairan terbuka) \\
\hline Gelombang (m) & $\leq 0,3$ & $>0,3-\leq 0,5$ & $>0,5$ \\
\hline Kedalaman (m) & $8,0-20,0$ & $5,0-<8,0:>20,0-25,0$ & $<5,0:>25,0$ \\
\hline $\operatorname{Arus}(\mathrm{m} / \mathrm{dtk})$ & $0,20-0,40$ & $0,05-<0,20:>0,40-\leq 0,50$ & $<0,05:>0,50$ \\
\hline Substrat Dasar & Pasir, pecahan karang, karang & Pasir berlumpur & lumpur \\
\hline Kecerahan (m) & $80-100$ & $60-<80$ & $<60$ \\
\hline DO (mg/l) & $5,0-8,0$ & $3,0-<5,0$ & $<3,0:>8,0$ \\
\hline BOT (ppm) & $21,0-25,0$ & $10,0-<21,0:>25,0-\leq 50,0$ & $<10,0:>50,0$ \\
\hline Suhu $\left({ }^{0} \mathrm{C}\right)$ & $27,0-33,0$ & $20,0-<27,0$ & $<20,0:>33,0$ \\
\hline Salinitas (ppt) & $30,0-35,0$ & $25,0-<30,0$ & $<25,0:>35,0$ \\
\hline
\end{tabular}


Parameter kualitas air, Amoniak, $\mathrm{pH}$, temperatur, nitrit, turbiditas, diukur menggunakan Water Test Kit AYI-10 in ScienPro. Sementara salinitas dan oksigen terlarut (DO) diukur menggunakan Water Tester Horiba.

Data hasil pengamatan parameter fisika kimia dari perairan Bolaang Mongondow Selatan akan dibandingkan dengan baku mutu parameter kualitas air yang layak dan sesuai untuk lokasi akuakultur rumput laut (Tabel 1) dan KJA (Tabel 2).

Kriteria kesesuaian disusun berdasarkan parameter biofisik yang relevan dengan setiap kegiatan, dan dibuat dengan mengacu pada matriks kriteria kesesuaian (Sirajuddin, 2009). Tingkat kesesuaian dibagi atas tiga kelas yaitu Kelas S1 (sangat sesuai/highly suitable), Kelas S2 (sesuai/ suitable), Kelas N (tidak sesuai/not suitable). Kelas kesesuaian lahan terbagi ke dalam 3 kelas yang didefenisikan sebagai berikut (Sirajuddin, 2009):

1. Kelas S1 (sangat sesuai).

Perairan/lahan tidak mempunyai pembatas yang berat untuk suatu penggunaan secara lestari atau hanya mempunyai pembatas yang tidak berarti dan tidak berpengaruh secara nyata terhadap produksi, serta tidak akan menaikkan input dari apa yang telah diberikan.

2. Kelas S2 (sesuai).

Perairan/lahan mempunyai pembatas-pembatas untuk suatu penggunaan yang lestari. Ini akan mengurangi produktivitas dan keuntungan, serta meningkatkan input yang diperlukan

3. Kelas N (tidak sesuai).

Perairan/lahan mempunyai pembatas yang sangat berat, sehingga tidak mungkin untuk digunakan bagi penggunaan yang lestari.

\section{HASIL DAN PEMBAHASAN}

Data hasil penelitian untuk menentukan lokasi yang sesuai umtuk budidaya rumput laut di perairan Bolaang Alongondow Selatan ditampilkan pada Tabel 3, Nilai parameter fisika-kimia perairan desa Matandoi berada dalam selang kelas yang sesuai unttk budidaya rumput laut. Jika dibandingkandengan baku mutu perairan seperti yang ditetapkan pada tabel matriks kesesuaian lahan budidaya rumput laut, maka 6 parameter yang dikaji yakni substrat dasar, nitrat, kekeruhan, suhu, salinitas, dan $\mathrm{pH}$, berada dalam selang kelas $\mathrm{S} 1$. Sedangkan 6 parameter lainnya yakni keterlindungan, tinggi gelombang, kecepatan arus, kecerahan, kedalaman dan oksigen terlarut, berada dalam selang kelas S2. Dengan demikian dapat disimpulkan bahwa perairan pantai desa Matandoi merupakan per- airan yang sesuai untuk lokasi budidaya rumput laut.

Tabel 3. Nilai parameter fisika-kimia pada perairan desa Matandoi untuk budidaya rumput laut.

Table 3.Physical and chemical parameters in Matandoi village for seaweed culture.

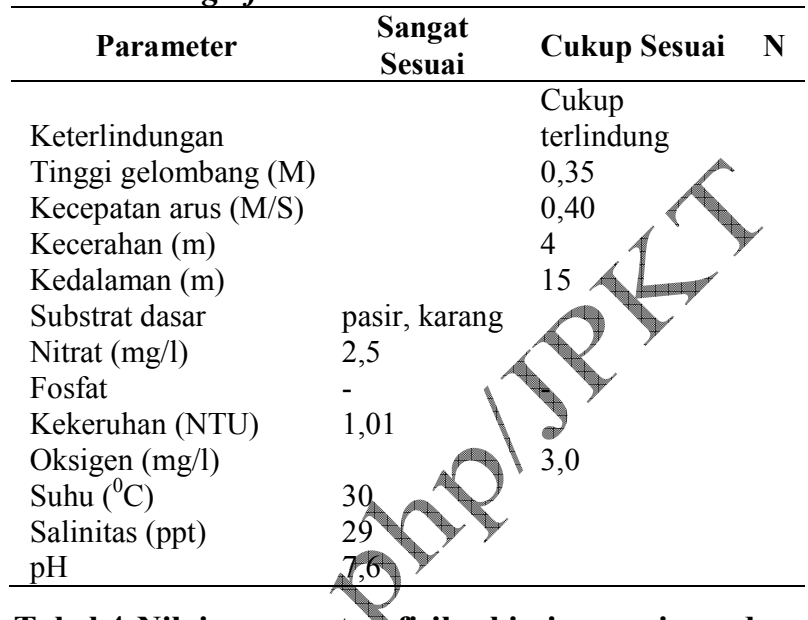

Tabel 4. Nilai parameter fisika-kimia perairan desa Matandố untuk budidaya ikan pada KJA.

Table 4.Physical and chemical parameters in Matandoi village for fishnet cage culture.

\begin{tabular}{lccc}
\hline Parameter & $\begin{array}{c}\text { Sangat } \\
\text { Sesuai }\end{array}$ & $\begin{array}{c}\text { Cukup } \\
\text { Sesuai }\end{array}$ & N \\
\hline Keterlydungan & Terlindung & \\
Gelombang (m) & & 0,3 \\
Kedalaman (m) & 0,25 & 5,0 \\
Arus (m/dtk) & $\begin{array}{l} \\
\text { Substrat dasar } \\
\text { pasir, pecahan } \\
\text { karang }\end{array}$ & \\
Kecerahan (m) & & 60 \\
Do (mg/l) & & 3,0 \\
Suhu ${ }^{\mathrm{c}}$ & 30 & \\
Salinitas & & 29 \\
\hline
\end{tabular}

Parameter fisika-kimia yang dikaji untuk perairan desa Matandoi, ada 4 parameter yang masuk selang kelas S1 yakni: keterlindungan, kecepatan arus, substrat dasar, dan suhu, sedangkan 5 parameter lainnya yakni, tinggi gelombang, kecerahan, kedalaman, oksigen terlarut dan salinitas berada dalam selang kelas S2 (Tabel 4). Untuk desa Torosik, enam parameter (keterlindungan, gelombang, kedalaman, kecepatan arus, substrat dasar dan suhu) berada dalam selang kelas S1, sedangkan kecerahan, oksigen terlarut dan salinitas berada dalam selang kelas S2 (Tabel 5). Untuk desa Pinalantungan, 5 parameter (keterlindungan, kedalaman, kecepatan arus, substrat dasar dan salinitas) berada dalam selang kelas S1, sedangkan tinggi gelombang, kecerahan, oksigen terlarut dan suhu berada dalam selang kelas S2 (Tabel 6). Untuk desa Deaga, 3 parameter (keterlindungan, arus, dan suhu) berada dalam selang kelas S1, sedangkan tinggi gelombang, kedalaman, substrat dasar, oksigen terlarut dan salinitas berada dalam selang kelas S2, 
sementara kecerahan, masuk dalam selang kelas $\mathrm{N}$ (Tabel 7).

Tabel 5. Nilai parameter fisika-kimia perairan desa Torosik untuk budidaya KJA.

Table 5.Physical and chemical parameters in Torosik village for fishnet cage culture.

\begin{tabular}{lccc}
\hline \multicolumn{1}{c}{ Parameter } & $\begin{array}{c}\text { Sangat } \\
\text { Sesuai }\end{array}$ & $\begin{array}{c}\text { Cukup } \\
\text { Sesuai }\end{array}$ & N \\
\hline Keterlindungan & terlindung & \\
Gelombang (M) & 0,20 & \\
Kedalaman (m) & 15 & \\
Arus (m/dtk) & 0,20 & \\
Substrat dasar & pasir, karang & \\
Kecerahan (m) & & 70 \\
Do $(\mathrm{mg} / 1)$ & & 3,0 \\
Suhu $\left({ }^{0} \mathrm{C}\right)$ & 30 & \\
Salinitas & & 28 \\
\hline
\end{tabular}

Tabel 6. Nilai parameter fisika-kimia perairan desa Pinalantungan untuk budidaya KJA.

Table 6. Physical and chemical parameters in Pinalantungan village for fishnet cage culture.

\begin{tabular}{lccc}
\hline \multicolumn{1}{c}{ Parameter } & $\begin{array}{c}\text { Sangat } \\
\text { Sesuai }\end{array}$ & $\begin{array}{c}\text { Cukup } \\
\text { Sesuai }\end{array}$ & N \\
\hline Keterlindungan & terlindung & \\
Gelombang $(\mathrm{M})$ & 18 & 0,4 \\
Kedalaman $(\mathrm{m})$ & 0,30 & \\
Arus $(\mathrm{m} / \mathrm{dtk})$ & $\begin{array}{c} \\
\text { pusir, pecahan } \\
\text { karang }\end{array}$ & \\
Kecerahan $(\mathrm{m})$ & & 5,0 \\
Do $(\mathrm{mg} / \mathrm{l})$ & & 4,0 \\
Suhu $\left({ }^{0} \mathrm{C}\right)$ & & 2,6 \\
Salinitas & 30 & & \\
\hline
\end{tabular}

Tabel 7.Nilai parameter fisika-kimia perairan desa Deaga untuk budidaya KJA.

Table 7.Physical and chemical parameters in Deaga village for fishnet cage culture.

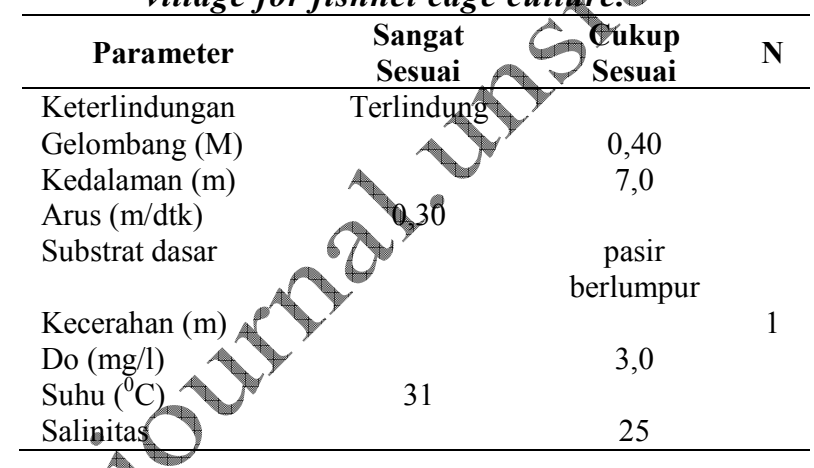

Parameter fisika-kimia perairan Bolaang Mongondow Selatan (desa Matandoi, Torosik dan Pinalantungan) untuk menentukan lokasi yang sesuai aktivitas budidaya ikan bersirip pada KJA berada dalam selang kelas yang S2. Jika dibandingkan dengan baku mutu perairan seperti yang ditetapkan pada tabel matriks kesesuaian lahan budidaya KJA, maka tiga lokasi tersebut dapat dikategorikan sebagai lokasi yang sesuai untuk budidaya ikan pada KJA. Perairan desa Deaga dikategorikan kurang sesuai untuk budidaya ikan pada KJA.

Keterlindungan (sheltering area), dimana lokasi budidaya di nilai sejauh mana dipengaruhi oleh angin dan gelombang yang besar, merupakan parameter utama dalam penentuan lokasi (Hidayat, 1990; Beveridge, 1991; Sade, 2006). Semua lokasi perairan yang di observasi baik untuk budidaya rumput laut maupun budidaya ikan pada KJA masuk dalam kategori perairan yang terlindung atau cukup terlindung. Meskipun perairan Bolaang Mongondow Selatan menghadap ke Selatan, sehingga berhadapan langsung dengan tiupánangin selatan. Akan tetapi semua lokasi yang diprlih sebagai lokasi budidaya adalah perairan yang menjorok ke arah daratan atau perairan teluk. Beberapa lokasi juga memiliki rataan terumbu penghalang, yang dapat menghalangi gelonbang sebelum mencapai pantai. Meskipun demikian, para pembudidaya rumput laut maupun pembudidaya ikan di KJA harus memperhifungkân pengaruh ombak dan angin pada musim-musim angin barat, barat daya dan selatân. Ketiga arah angin ini sering kali sangat kencang dan menyebabkan gelombang yang sangat tinggi (Salindeho, 2003; Salindeho, 2006). Selajutnya Sondakh (2009) menyatakan bahwa, daerah pesisir pantai Selatan Kabupaten Bolaang Mongondow, tidak lepas dari pengaruh iklim tropis dengan pola musim panas dari bulan April sampai September dan musim hujan dari Oktober hingga Maret. Musim kemarau umumnya mengakibatkan tiupan angin dari arah Selatan. Saat musim penghujan arah angin akan cenderung dari arah barat dan barat daya.

Ketinggian gelombang merupakan parameter penunjang yang diperhitungkan baik untuk lokasi budidaya rumput laut maupun budidaya ikan di KJA (Beveridge, 1991). Ketinggian gelombang yang direkam pada semua lokasi berada pada kisaran antara $0,2-0,4 \mathrm{~m}$, yang mengindikasikan semua lokasi tersebut aman dari ancaman gelombang yang besar. Parameter ketinggian gelombang merupakan fungsi dari parameter keterlindungan. Artinya semakin terlindung suatu lokasi, maka semakin kecil diameter gelombangnya, demikian sebaliknya. Karena semua lokasi yang di observasi merupakan daerah terlindung maka akibatnya ketinggian gelombang pada lokasi-lokasi tersebut juga nilainya kecil. Untuk budidaya ikan pada KJA, gelombang harus dihindari karena dapat berdampak negatif pada ikan dalam kantong kurungan maupun bagi konstruksi KJA. Untuk budidaya rumput laut, gelombang yang kontinyu dengan ketinggian tertentu sangat dibutuhkan untuk mem- 
bantu dalam menjaga kebersihan talus rumput laut (Hidayat, 1990). Oleh karena itu ketinggian gelombang untuk lokasi yang sangat sesuai untuk budidaya rumput laut berada pada kisaran antara $0,2-0,3 \mathrm{~m}$.

Kecepatan arus merupakan parameter utama yang penting diukur pada penelitian ini, karena arus sangat berperan penting untuk keberhasilan baik budidaya rumput laut maupun ikan di KJA. Lokasi yang memiliki arus yang terlalu lemah tidak layak untuk lokasi budidaya, namun arus yang terlalu cepat juga dapat merusak konstruksi wadah dan dapat melepaskan talus rumput laut dari ikatan. Kecepatan arus yang direkam pada semua lokasi budidaya ikan di KJA berada pada kisaran antara $0,2-0,3 \mathrm{~m} /$ detik, yang mengindikasikan semua lokasi tersebut masuk kategori sangat sesuai. Kecepatan arus pada lokasi budidaya rumput laut di perairan desa Matandoi yang sebesar $0,4 \mathrm{~m} /$ detik, berada pada ambang batas atas untuk kategori cukup sesuai, atau dengan kata lain jika nilai tersebut lebih besar sedikit dari 0,4 m maka lokasi tersebut akan diketegorikan tidak sesuai dari aspek kecepatan arus.

Pada budidaya rumput laut, arus berfungsi untuk membawa nutrien yang sangat dibutuhkan oleh rumput laut dalam pertumbuhannya (Hidayat, 1990). Pergantian air secara terus-menerus dibutuhkan agar selalu ada massa air yang baru yang membawa nutrien dengan komposisi yang lengkap dalam jumlah yang cukup (Vairappan and Chung, 2006). Arus air juga harus dijamin mencapai ke semua rumput laut pada seluruh lokasíbudidaya. Pada lokasi budidaya dengan kepadatan rumput laut yang sangat tinggi, kadang kala arus menjadi sulit untuk menembus sampai ke semua bagian sudut lokasi budidaya. Akibatnya ada bagian yang tidak mendapat pergantian air yang cukup. Oleh karena itu layout dafi wadah budidaya rumput laut harus di tata sedemikian rupa agar semua ikatan rumput laut pada semua tali ris mendapatkan pergantian air secara terus-menerus sesuai kebutuhannya.

- Pada budidaya ikan dalam KJA, arus merupakanfaktor yang esensial untuk pertumbuhan ikan dalam kurungan. Arus berfungsi untuk membawa massa air baru yang mengandung oksigen yang cukup untuk aktivitas respirasi ikan. Arus juga membawa sisa-sisa pakan, faeces dan buangan metabolik ikan keluar jauh dari kurungan, serta membawa pakan alami ke dalam KJA (Beveridge, 1991). Arus yang terlalu cepat tidak dikehendaki karena akan memberikan gaya dinamis yang besar pada sistem KJA sehingga berpe- ngaruh pada sistem keamanan. Selain itu arus yang terlalu kuat akan menyebabkan deformasi kantong jaring, yang menyebabkan volume kantong berkurang hingga $70 \%$ dari volume kantong yang sebenarnya (Beveridge, 1991). Kondisi seperti ini menyebabkan ikan dalam kondisi sangat padat di ruang yang tersisa, sehingga ikan behimpitan dan dapat menyebabkan luka karena ikan berontak saat berdesakan. Ramelan (1998) menyatakan bahwa kecepatan arus untuk akuakultur ikan dalam.KJA harus berada pada kisaran $20-40 \mathrm{~cm} /$ detik.

Kedalaman perairan dari lima lekkasi yăng diobservasi bervariasi antara 5-18 m. Kledataman perairan merupakan parameter penunjang untuk budidaya rumput laut. Kedalaman perairan minimal merupakan faktor pembatas untuk pertumbuhan rumput laut, sedangkan tidak lada batasan maksimal yang dapat mempengaruhi pertumbuhan rumput laut (Hidayat, 1994). Kedalaman minimal ditentukan oleh titik dimana terjadi surut terendah dari perairan tersebut, ssehingga kedalaman lokasi budidaya sebaiknya masih berkisar $0,5 \mathrm{~m}$ dari level air pada surutterendah. Perairan yang terlalu dalam, misalnya febih besar dari $10 \mathrm{~m}$ mengakibatkan material kanstruksi wadah menjadi lebih banyak dan lebih mahal, karena mooring system atau sistem penambatan akan menggunakan lebih banyak material dan instalasi di lapangan menjadi lebih kompleks (Hidayat, 1990). Selain itu operasional pembersihan harian akan menjadi lebih mahal.

Untuk budidaya ikan di KJA, kedalaman perairan yang minimal ditentukan oleh dimensi kantong jaring, beda pasang-surut dan jarak minimal antara dasar kantong dan dasar perairan. Jika kantong jaring memiliki tinggi $3 \mathrm{~m}$, beda pasangsurut sebesar $2 \mathrm{~m}$ kemudian jarak antara dasar perairan dan dasar kantong sebesar $2 \mathrm{~m}$, maka kedalaman minimal lokasi KJA harus sedikitnya $7 \mathrm{~m}$. Ramelan (1998) menyatakan bahwa kedalaman perairan untuk akuakultur ikan dalam KJA harus $>8 \mathrm{~m}$. Pertimbangan untuk kedalaman maksimal juga ditentukan oleh mahalnya material konstruksi, khususnya mooring system, besarnya biaya operasional serta sulitnya proses instalasi system KJA (Beveridge 1991). Oleh karena itu kedalaman perairan untuk KJA lebih baik tidak lebih dari $15 \mathrm{~m}$.

Substrat dasar perairan juga merupakan parameter penunjang untuk penentuan lokasi budidaya rumput laut dan ikan dalam KJA. Untuk kedua lokasi budidaya, substrat yang dikehendaki adalah yang baik adalah pasir, pecahan karang dan karang (Sade, 2006; Vairappan and Chung, 2006). Sedangkan yang harus dihindari adalah substrat dengan kombinasi lumpur, karena akan sangat 
memberikan dampak pada kecerahan atau kekeruhan perairan pada saat ada arus dan gelombang (Hidayat, 1990). Di antara semua lokasi yang di observasi, 4 lokasi memiliki substrat pasir berkarang, hanya perairan desa Deaga yang memiliki substrat pasir berlumpur. Akibatnya, kecerahan perairan desa Deaga sangat kecil, yakni $1 \mathrm{~m}$, sehingga perairan ini masuk dalam kategori perairan yang kurang layak untuk lokasi budidaya ikan dalam KJA, maupun rumput laut. Ke-empat lokasi yang lain memiliki kecerahan antara 4-7 m.

Nilai kecerahan berbanding terbalik terhadap nilai kekeruhan, dimana kekeruhan yang tinggi menyebabkan nilai kecerahan menjadi rendah. Kekeruhan berhubungan dengan partikel tersuspensi serta lumpur yang ada di dasar perairan yang naik ke kolom air pada saat ada gelombang atau arus. Lokasi budidaya di perairan Matandoi memiliki nilai kekeruhan 1,01 NTU, yang masuk dalam kategori sangat sesuai. Lokasi dengan nilai kekeruhan yang tinggi harus dihindari untuk aktivitas budidaya. Kekeruhan yang tinggi dari suspended solids tidak baik untuk kegiatan budidaya rumput laut karena mengurangi penetrasi cahaya ke dalam air sehingga mengganggu proses fotosintesis rumput laut; dan juga menutup permukaan talus sehingga menghambat absorbsi nutrien melalui permukaan talus (Hidayat, 1990; Ditjen Perikanan Budidaya, 2005; Vairappan and Chung, 2006).

Untuk budidaya ikan di KJA, kekeruhan yang tinggi dapat berakibat terganggunya sistem osmoregulasi, menurunkan daya lihat organisme akuatik dan mengganggu fungsi insarg dan menurunkan tingkat respirasi atau pernafasan serta memicu pembentukan bio-fouling pada struktur KJA sehingga meningkatkan gaya statis dan dinamis dari sistem KJA (Landau, 1995). Dengan alasanalasan tersebut maka Tokasi perairan Deaga yang memiliki tingkat kecerăhan $1 \mathrm{~m}$, dikategorikan kurang sesuai untuk lokasi budidaya ikan di KJA.

Nutrien dalam konteks kualitas air adalah molekul-molekŭl dalam air yang dapat langsung digunakan oteh tumbuh-tumbuhan untuk pertumbuhan selnya (Landau, 1995). Di perairan laut, nitrat $\mathrm{NO}_{3}$ ) merupakan nutrien terpenting yang menentukan pertumbuhan plankton dan tumbuhan tingkat tinggi. Oleh karena itu, nitrat merupakan parameter utama dalam penentuan lokasi budidaya rumput laut (Landau, 1995). Kandungan nitrat perairan desa Matandoi yang sebesar $2,5 \mathrm{mg} / \mathrm{L}$, masuk dalam kategori sangat sesuai untuk lokasi budidaya rumput laut.

Suhu merupakan parameter utama dalam menentukan lokasi akuakultur. Secara umum, suhu perairan laut di daerah tropis tidak akan berbeda jauh dari satu lokasi ke lokasi perairan yang lain. Semua lokasi perairan yang di observasi untuk budidaya rumput laut maupun budidaya ikan di KJA memiliki suhu perairan yang berkisar antara 30$31^{\circ} \mathrm{C}$. Kisaran suhu demikian masuk dalam kategori perairan yang sangat sesuai untuk aktivitas akuakultur. Sementara Vairappan and Chung (2006) menyatakan suhu yang terbaik untuk pertumbuhan Kappaphycus adalah antara $25-30^{\circ} \mathrm{C}$. Selanjutnya dinyatakan bahwa perubahan drastis temperatur, baik naik atau turun, akan memicu terjadinya serangan penyakit padanya (Largo, 2006

Dalam menentukan lokasi kultur rumput laut maupun kultur ikan di KJA, oksigen terlarut (DO) merupakan parameter utama dan terpenting yang harus diperhitungkan (Eandau, 1995). Oksigen diperlukan oleh semua organisme hidup untuk proses respirasi, sehingga konsentrasi oksigen dalam perairan menjadífaktor pembatas untuk pertumbuhan (Landáa, 01995). Kandungan oksigen yang rendah dangsung menyebabkan ikan lemas dan jika tídak diberi perlakuan dapat terjadi mortalitas massalikan dalam KJA. Kadar oksigen terlarut pada semua lokasi perairan yang diobservasi berada pada kisaran antara 3-4 mg/L, sehingga semua lokasi, kultur rumput laut maupun kultur ikan pada KJA, hanya dikategorikan cukup sesuai sebagai lokasi budidaya. Sebab lokasi yang dikategorikan sangat sesuai, baik untuk kultur rumput laut maupun kultur ikan dalam KJA harus memiliki kadar oksigen terlarut $>4 \mathrm{mg} / \mathrm{L}$.

Salinitas merupakan parameter yang krusial untuk kultur dari setiap komoditas organisme laut. Setiap spesies organisme laut memiliki kisaran toleransi yang spesifik untuk pertumbuhan optimal (Landau, 1995). Salinitas secara langsung mempengaruhi proses osmoregulasi dari setiap organisme akuatik, sehingga salinitas yang tidak sesuai dengan kebutuhan organisme tertentu atau fluktuasi salinitas yang berulang-ulang dengan kisaran yang tinggi akan mengganggu semua fungsi fisiologis ikan. Akibatnya ikan hanya mengalokasikan energi bukan untuk pertumbuhan namun untuk menormalkan fungsi tubuh (Landau, 1995). Bahkan sebagian besar ikan akan mengalami stress bahkan pada kondisi perubahan salinitas yang ekstrim dapat berakibat tingginya kematian.

Untuk lokasi budidaya rumput laut, level salinitas yang sangat sesuai adalah antara 28-34 ppt. Sedangkan persyaratan untuk lokasi budidaya rumput laut yang dirilis oleh Ditjen Perikanan $\mathrm{Bu}-$ didaya (2005) menetapkan kisaran nilai salinitas yang lebih besar yakni antara 28-35 ppt. Perubah- 
an salinitas tiba-tiba secara drastis, baik naik atau turun, menjadi pemicu serangan penyakit pada Kappaphycus (Largo, 2006; Vairappan and Chung, 2006) Sedangkan untuk budidaya ikan dalam KJA, kisaran salinitas yang terbaik sangat tergantung pada ikan yang dipelihara. Ada ikan yang memiliki kemampuan untuk hidup dan bertumbuh baik pada kisaran salinitas yang besar, namun ada ikan hanya bisa hidup dan bertumbuh pada kisaran Salinitas yang kecil. Satu hal yang sangat penting dihindari dalam aktivitas akuakultur adalah lokasi yang mempunyai potensi fluktuasi yang tinggi seperti muara sungai (Hidayat, 1990; Ditjen Perikanan Budidaya, 2005; Sade, 2006; Vairappan and Chung, 2006).

Nilai $\mathrm{pH}$ untuk lokasi budidaya rumput laut seperti yang disyaratkan pada tabel 1 adalah 78,5. Sedangkan persyaratan untuk lokasi budidaya rumput laut yang dirilis oleh Ditjen Perikanan $\mathrm{Bu}-$ didaya (2005) menetapkan range nilai $\mathrm{pH}$ yang lebih besar yakni antara 6,5-8,5. Perairan laut memiliki sistem buffer dalam menjaga agar level $\mathrm{pH}$ tetap stabil, sehingga nilai $\mathrm{pH}$ tidak akan berfluktuasi pada range yang besar (Landau, 1995).

\section{KESIMPULAN}

Berdasarkan hasil penelitian menyangkut kesesuaian lahan perairan laut Kabupaten Bolaang Mongondow Selatan untuk budidaya rumput faut dan budidaya ikan di KJA dapat disimpulkan bahwa perairan desa Matandoi sesuai untuk Yokåsi budidaya rumput laut. Perairan desa Prnalantungan, Torosik dan Matandoi sesuai untuk tokasi budidaya ikan pada KJA, sedangkan perairan desa Deaga kurang sesuai untuk lokasi budidaya KJA.

\section{DAFTÂR PUSTAKA}

Anonimous. 2011. Profil Kabupaten Bolaang Mangondow Selatan: Potensi Perikanan. Antaranews.com. http://www. antarasulut com/berita/12794/profil-kabupaten-bolaangmongondew-selatan. Date visited: 03-06-2013.

Beveridge M. 1991. Cage Aquaculture, Fishing News Books. USA ETsevier. Amsterdam. p 264.

Departemen Kelautan dan Perikanan, 2002. Pedoman Umum Pemanfaatan Ruang Pesisir dan Pulau-pulau Kecil. SK. Menteri Kelautan dan Perikanan no 34/Men/2002. 108 p.

Effendi H. 2000. Telaahan Kualitas Air: Bagi pengelolaan sumberdaya dan lingkungan perairan. Institut Pertanian Bogor. 259 p.

Hidayat A. 1990. Budidaya Rumput Laut. Usaha Nasional. Surabaya. 96 p.
Keppel RC. dan Salindeho IRN. 2004. Potensi budidaya rumput laut di Sulawesi Utara. Jurnal Perikanan dan Ilmu Kelautan, FPIK, UNSRAT. 2(3): 24-29.

Landau M. 1995. Introduction to Aquaculture. John Willey \& Sons, Inc. New York. 440 p.

Largo BD. 2006. Diseases in cultivated seaweeds in the Philippines: is it an issue among seaweed industry players In Advances in Seaweed Cultivation and Utilization in Asia. Moi SP., Critchley AT. and Ang PO. (Eds.). Proceedings of a workshop $7^{\text {th }}$ Asian Fisheries Forum, Malaysia. Maritime Research Centre, University of Malaya. p 61-70.

Nang QH. and Isao T. 2006. Kappaphycus cultivation and utilization in Vietnam. In Advances in Seaweed Cultivation and Utilization in Asia. Moi SP., Critchley AT. and

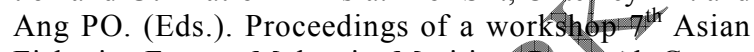
Fisheries Forum, Malaysia. Maritime Research Centre, University of Malaya. p 171-177

Nasution S. 2009. Metode Research (Penelitian ilmiah). Bumi Aksara. Jakarta. 156 p.

Ramelan HS. 1998. Pengembangap budidaya ikan laut di Indonesia dalam: Kumpuian makxlah seminar teknologi perikanan pantai. Deppasar 6-7 Agustus 1998. Balitbang Departemen Petanian dah JICA. p 1-37.

Sade A. 2006. Seaweed industry in Sabah, East Malaysia. In Advances in Seaweed Cultivation and Utilization in Asia. Moi SP., Critchley AT. and Ang PO. (Eds.). Proceedings of a workshop 7th Asian Fisheries Forum, Malaysia. Maritime Research Centre, University of Malaya. p 41-52.

SalindehorRN. 2006. Laporan projek pengelolaan sumberda-

A ya laut dan pesisir skala kecil (Small Scale-MCRMP) di Kabupaten Minahasa, Prov. Sulut, 2006. Bappeda Minahasa. 200 p.

Salindeho IRN. 2003. Laporan projek adaptive research and extension 2003 di Kabupaten Boalemo, Prov. Gorontalo. Bappeda Boalemo. 100 p.

Sirajuddin M. 2009. Informasi awal tentang kualitas biofisik perairan Teluk Waworada untuk budidaya rumput laut (Eucheuma cottonii). Jurnal Akuakultur Indonesia, FPIK. IPB. 8 (1): 1-10.

Sondakh S. 2009. Profil desa nelayan Loyow, Kecamatan Nuangan, Kabupaten Bolaang Mangondow. Jurnal Perikanan dan Kelutan, FPIK, UNSRAT, 5(2): 51-57.

Sugama K. 2011. Kondisi terkini sumberdaya ikan hasil budidaya dalam mendukung industrialisasi perikanan. Materi kuliah umum UGM, 12 November 2012. Ditjen Perikanan Budidaya, Kementerian Kelautan dan Perikanan.

Sutisna DH. 2011. Kondisi terkini sumberdaya ikan hasil tangkapan dalam mendukung industrialisasi perikanan. Ditjen Perikanan Tangkap. Kementerian Kelautan dan Perikanan.

Vairappan CS. and Chung CS. 2006. Seaweed farming in Malaysia: Challenges. In advances in seaweed cultivation and utilization in Asia. Moi SP., Critchley AT. and Ang PO. (Eds.). Proceedings of a workshop $7^{\text {th }}$ Asian Fisheries Forum, Malaysia.Maritime Research Centre, University of Malaya. p 161-169. 